\title{
Potential of Wireless Power Transfer for Dynamic Charging of Electric Vehicles
}

\author{
Luke Hutchinson $^{1 *}$, Ben Waterson ${ }^{1}$, Bani Anvari ${ }^{1}$, Denis Naberezhnykh ${ }^{2}$ \\ ${ }^{1}$ Transportation Research Group, University of Southampton, Southampton, United Kingdom \\ ${ }^{2}$ Transport Research Laboratory, Wokingham, United Kingdom \\ *L.Hutchinson@southampton.ac.uk
}

\begin{abstract}
Wireless Power Transfer (WPT) offers a viable means of charging Electric Vehicles (EV)'s whilst in a dynamic state (DWPT), mitigating issues concerning vehicle range, the size of on-board energy storage and the network distribution of static based charging systems. Such Charge While Driving (CWD) technology has the capability to accelerate EV market penetration through increasing user convenience, reducing EV costs and increasing driving range indefinitely, dependent upon sufficient charging infrastructure. This paper reviews current traction battery technologies, conductive and inductive charging processes, influential parameters specific to the dynamic charging state as well as highlighting notable work undertaken within the field of WPT charging systems. DWPT system requirements, specific to the driver, vehicle and infrastructure interaction environment are summarised and international standards highlighted in order to acknowledge the work that must be done within this area. It is important to recognise that the gap is not currently technological; instead, it is an implementation issue. Without the necessary standardisation, system architectures cannot be developed and implemented without fear of interoperability issues between countries or indeed systems. For successful deployment, the technologies impact should be maximised with the minimum quantity of infrastructure and technology use, deployment scenarios and locations are discussed that have the potential to bring this to fruition.
\end{abstract}

\section{Introduction}

The electrification of road transport provides a viable means of reducing fossil fuel consumption and environmental pollution, hence the recent advancements in Electric Vehicle (EV) design and performance [1]. However, the high costs and poor specific energy densities of batteries compared to fossil fuels results in a less than ideal scenario [2]. Due to their relatively shorter range, EV's require more frequent charging (than refuelling of Internal Combustion Engine (ICE) vehicles) to maintain a desirable range and with long charge times (compared with conventional refuelling times) or potential battery degradation that occurs during rapid charging; battery charging technology has restricted EV development. With no significant advancements in battery technology that would bring EV range in line with comparable ICE vehicles forecasted within the foreseeable future [3] this has resulted in substantial research into alternative charging methods. Whilst conventional plug in charging is the most common form, there are still conductive energy losses within the system resulting in an overall efficiency of around $86 \%$ [4] and potentially lower for rapid chargers. In addition, the high power transfer, human handling and the ability for the user to forget to plug in/out result in a pragmatic scenario.

Wireless Power Transfer (WPT) technology is capable of mitigating the issues of plug in charging; the EV is parked over a coil that inductively transfers electrical energy to a receiver coil positioned on the vehicle. This static process does little to mitigate the issues concerning frequent $\mathrm{EV}$ charging and the requirement of a large battery capacity on the vehicle. The ability to use WPT in a dynamic state (DWPT), whilst the vehicle is driven, has the possibility to increase driving range indefinitely, dependent upon sufficient charging infrastructure to support this. Further, WPT studies have shown that battery capacity can be reduced to $20 \%$ [5]; thus eliminating issues concerning both heavy and expensive battery packs. This reduction in on-board battery storage will consequently reduce EV costs whilst increasing energy efficiency through lightweighting [6]. Inevitably, energy losses result in a reduction of system efficiency over that of conductive systems; however, research has shown that DWPT systems can achieve efficiencies greater than $90 \%$ through the direct transfer of power to the power train, bypassing the vehicle battery [7]. However, both static and dynamic forms of WPT are susceptible to introduced errors such as coil misalignment and current transformation.

The aim of this paper is to understand the role of DWPT within future EV infrastructure and identify key challenges to achieving its potential. The contributions of this paper are as follows:

- This paper describes current traction battery technologies, conductive and inductive charging processes, Dynamic Wireless Power Transfer (DWPT) system requirements, and the international standards and codes associated to EVs.

- Conducts a detailed survey on dynamic wireless charging infrastructure fundamentals and their implementation issues.

- Highlights the current barriers and potential issues for supporting and accelerating EVs' growth, with emphasis on the need for standardisation. 
This paper is organised as follows: EV fundamental theory concerning traction battery technology, charging methods, magnetic coupling and the DWPT process are discussed within Section 2. Section 3 details the vehicle and infrastructure fundamentals of DWPT technology and how the interaction environment between the two has a great effect on achievable transfer efficiency. An assessment into state-of-the-art industry WPT systems is undertaken within Section 4 and issues over their interoperability are highlighted. International Standards of EV's and associated technologies are highlighted within Section 5, concluding remarks are made with respect to the benefits, challenges and barriers that are associated to DWPT charging systems.

\section{Electric Vehicle Fundamentals}

An EV consists of three major power sub-systems; an electric battery, an electric motor and a controller that controls the motor power supply and ultimately vehicle speed and direction. Until 2010, the lack of EV technology capability has resulted in the market domination of Internal Combustion Engine (ICE) vehicles. However, recent advancements in EV technology, notably motor design and Lithium Ion (Li-Ion) batteries, have seen market penetration and take-up of numerous EV's. The increasing awareness of energy conservation and environmental protection has seen policymakers generate a shift towards low carbon vehicles, further accelerating the market penetration of EV's [8]. Norway has been able to accelerate their take up of EV's, substantial subsidy and taxation policies have resulted in a $29 \%$ EV market share [9] and the plan to ban fossil fuelled vehicles within the next decade [10].

The recent rise in EV ownership and the increasing travel distance of commuters [11] has led to further demand being placed upon battery storage technology and the charging network to support EV's. The battery is one of the most expensive components of an EV; without major breakthroughs in energy storage capacity, it is unlikely that EV range will significantly increase. Therefore, to compensate for the lack of EV range, the charging network has been the subject of much investment with the installation of charging points at residential properties, workplaces, service stations, city centres and many other points of interest. Whilst these charging points are made up of both standard and rapid charging technologies, the requirement for the vehicle to be stationary for the given charging time is still an issue. DWPT provides a viable means to utilise EV in-motion charging and increasing EV range indefinitely.

\subsection{Current Electric Vehicle Batteries}

Energy storage capacity is a growing concern as the modern world continues to distance itself from fossil fuel derived energy sources [12], advancements in energy storage is necessary to resolve many of the supply reliability issues of renewable technologies [13]. The on-board battery storage of EV's also follows this trend, therefore the lack of battery capacity and energy density advancements has the potential to restrict the continued development and market take-up of EV's. Energy storage breakthroughs are also an essential component for the development cycle of low carbon technologies and the continual progression to lower carbon vehicles [14].

Properties of EVs and Plug-In Hybrid Electric Vehicles (PHEVs) are summarised in Table 1. Li-Ion traction batteries are now commonplace in most EV's [15], due to their high energy density to volume (Wh/l) and mass ratios $(\mathrm{Wh} / \mathrm{kg})$, such batteries also have good power densities, very little or no memory effect, long lifespan, low self-discharge and fast charge times when compared to other battery types, notably Lead Acid and Nickel-Metal-Hydride $(\mathrm{Ni}-\mathrm{MH})$ [16]. However, Li-ion batteries are sensitive to high temperatures that reduce battery performance and risk cell ignition; they are also expensive to manufacture [17].

There are a number of EV battery technologies under development (see Table 1) but whilst Li-Ion batteries have a lower specific energy, their high specific power, energy efficiency and cycle life mean that they are the most suitable technology for traction batteries [18]. Costs of EV batteries are within the region of $\$ 227$ per $\mathrm{kWh}$ [19] but continue to decrease as technology and economies of scale develop, Tesla are reporting battery costs of $\$ 190$ per $\mathrm{kWh}$ [20]. In addition, the power to mass ratio of traction batteries, typically $60-96 \mathrm{Wh} / \mathrm{kg}$ [21], is poor when compared to other fossil fuel sources. The range of EV's is expected to double by 2020 (at 2015 battery capacities) because of advancements in EV battery design. Several manufacturers [22], including Bosch (through acquisition of Seeo), are developing solid-state battery technology that has the potential to double battery storage at half the cost of current $\mathrm{EV}$ batteries. Yet, the average EV range is $\sim 100$ miles, doubling this distance still leaves a considerable gap between the ranges of ICE vehicles achieving in excess of 600 miles per tank. For freight vehicle applications, this is not even an option due to the great volume and mass requirements for traction batteries to achieve even a reasonable range.

Table 1 Properties of electric vehicle and plug-in electric vehicle batteries [18]

\begin{tabular}{lllll}
\hline Battery Type & $\begin{array}{l}\text { Specific Energy } \\
(\mathrm{Wh} / \mathrm{kg})\end{array}$ & $\begin{array}{l}\text { Specific Power } \\
(\mathrm{W} / \mathrm{kg})\end{array}$ & $\begin{array}{l}\text { Energy Efficiency } \\
(\%)\end{array}$ & Cycle Life \\
& & & & $500-1000$ \\
Lead-Acid & $35-50$ & $150-400$ & 80 & $1000-2000$ \\
Nickel-Cadmium & $30-50$ & $100-150$ & 75 & 1000 \\
Nickel-Metal-Hydride & $60-80$ & $200-400$ & 70 & N/A \\
Aluminium-Air & $200-300$ & 100 & $<50$ & 500 \\
Zinc-Air & $100-220$ & $30-80$ & 60 & 1000 \\
Sodium-Sulphur & $150-240$ & 230 & 85 & 1000 \\
Sodium-Nickel-Chloride & $90-120$ & $130-160$ & 80 & 1000 \\
Li-Polymer & $150-200$ & 350 & N/A & $>1000$ \\
Li-Ion & $90-160$ & $200-350$ & $>90$ &
\end{tabular}


Unlike traditional ICE vehicles, EV's are much more flexible in terms of their mechanical configuration [8]. Whilst they follow the typical aesthetical form of modern vehicles, due to the lack of mechanical drive components, EV's use wheel driven electric motors and specifically shaped battery packs for optimum vehicle packaging. The majority of battery packs are located on the floor pan of the vehicle to optimise weight distribution, lower the vehicles centre of gravity as well as for mechanical design and safety [23].

\subsection{Charging Methods for Electric Vehicles}

The need for EV charging is fundamental, electrical energy is not generated on-board the vehicle, instead it is generated externally and transferred to the traction batteries during the charging process. There are a number of different forms of $\mathrm{EV}$ charging, ultimately the present and future optimised charging network will feature an array of these different chargers that best suit location, charging demand, charging time, electricity supply and cost considerations. It is vital not to underestimate the importance of home charging; the ability to slowly charge the vehicle overnight at the EV owner's residence is both convenient and a cost effective means to refuel the vehicle. Scaling the current levels of home charging to a scenario with the high penetration of EVs may change the feasibility of home charging [24]; population growth, technology capabilities, energy and power availability, attitudes to energy consumption, market structures as well as potential changes in mobility are all factors that could influence charging behaviour.

Charging technologies can be divided into two main groups, conductive and inductive. The former consists of fixed-point plug-in chargers that provide a conductive connection between the vehicle and electricity grid, meanwhile inductive chargers are those that transmit electrical energy wirelessly using an electromagnetic coupling.

2.2.1 Conductive Charging: Whilst there are a number of EV charging international standards, EV owners are still overwhelmed by a large array of charging cables, plugs and types of chargers [25]. There are also several classifications of EV charging modes [26], all of which follow a similar premise; the subsequent outline follows the 'Electric vehicle conductive charging system: General requirements' BS EN 61851-1 standard [27]. Conductive systems can be categorised into Alternating Current (AC) and Direct Current (DC) chargers. AC systems utilise an on-board vehicle charger to rectify the AC to DC for battery charging, while DC chargers rectify the AC power supply to DC within the Electric Vehicle Supply Equipment (EVSE) before supplying it to the vehicle. The BS EN 61851-1 standard specifies four types of EV charging mode:

Mode 1 (AC): Non-dedicated circuit and socket outlet: The most basic form of vehicle charging; a charging cable connects the vehicle to standard household electrical sockets. Maximum current and power transfer is $13 \mathrm{~A}$ and $3 \mathrm{~kW}$ respectively for UK domestic 230V 3-pin plug applications [28]. This charging mode is not recommended for use due to the lack of control equipment; whilst 3-pin plugs are fused, there is no in-line Residual Current Device (RCD) to provide protection. Hence, within the UK, home chargers are now restricted to at least Mode 2 due to safety concerns [25].

Mode 2 (AC): Non-dedicated circuit and socket outlet, cable incorporated RCD: A Mode 2 charger features an in cable control box and a RCD to protect the system and user [29]. The control box ensures a protective earth conductive connection before the charging is commenced; it also monitors the battery and charging process. For domestic applications, a UK 3-pin plug is utilised and maximum current and power transfer is still limited to $13 \mathrm{~A}$ and $3 \mathrm{~kW}$ respectively. Many EV manufacturers limit residential Mode 2 charging power at $1.4 \mathrm{~kW}$ to $2.3 \mathrm{~kW}$ ( $6 \mathrm{~A}$ to $10 \mathrm{~A}$ ) for safety reasons. Maximum current and power can be increased to $32 \mathrm{~A}$ and $7.4 \mathrm{~kW}$ for industrial applications when utilising industrial connectors [30]. Whilst this charging mode features control equipment and RCD protection, it is only recommended for occasional use, as a back-up charging method when no dedicated charger is available, or for vehicles with limited charging requirements, such a PHEVs [25].

Mode 3 (AC): Dedicated EV charging system, dedicated outlet: Whilst Mode 1 and Mode 2 utilise existing domestic, and industrial connectors, Mode 3 features dedicated EVSE. Tethered cables are typically used, especially for domestic use, with specific EV connectors or for non-tethered applications dedicated EV sockets are provided [28]. Domestic applications (single phase) are typically $3.7 \mathrm{~kW}$ (16A) or $7.4 \mathrm{~kW}(32 \mathrm{~A})$. Commercial and public EVSE (three phase) are often capable of supplying higher power transfer limits to reduce charge time [30]. Modes 1-3 all supply AC to the vehicles on-board charger to convert to DC for battery charging, hence charge time remains limited by the capabilities of the on-board charger, regardless of AC power supply limits. Due to additional communication lines between the vehicle and EVSE, Mode 3 has potential for smart charging capabilities in the future.

Mode 4 (DC): Dedicated EV charging system, dedicated outlet: On-board vehicle chargers are constrained by volume, mass and cost; Mode 4 systems use a larger external charger that rectifies the AC power supply to DC before supplying it to the vehicle. Such rapid chargers bypass the on-board charger and are capable of power transfers in excess of $100 \mathrm{~kW}$, greatly reducing charge times. Such chargers are constrained to commercial depots and public locations because of power supply requirements and high capital costs [25]. Due to the high power transfer, tethered cables are used and similar control, protection and communication measures found in Mode 3 EVSE are again present. Typically, Mode 4 chargers are used to provide rapid onroute top-up charging. Tesla Motors use a $120 \mathrm{~kW} \mathrm{DC}$ charging system within their Supercharger (rapid charging) network, built exclusively for Tesla owners; however, this has led to a parallel charging infrastructure being built which is not an ideal scenario [31]. 
Table 2 Charge time of a $24 \mathrm{kWh}$ battery to $80 \%$ capacity [25]

\begin{tabular}{|c|c|c|c|c|c|}
\hline Current & $\begin{array}{l}\text { Maximum Power } \\
\text { Output }\end{array}$ & Charge Time & Input Voltage & $\begin{array}{l}\text { Maximum } \\
\text { Current }\end{array}$ & $\begin{array}{l}\text { Charging } \\
\text { Mode }\end{array}$ \\
\hline \multirow{7}{*}{$\mathrm{AC}$} & $2.3 \mathrm{~kW}$ & $8 \mathrm{hrs} 20 \mathrm{mins}$ & 230 1-phase AC & 10 & $2 / 3$ \\
\hline & $3 \mathrm{~kW}$ & $6 \mathrm{hrs} 30 \mathrm{mins}$ & 230 1-phase AC & 13 & $2 / 3$ \\
\hline & $3.7 \mathrm{~kW}$ & $5 \mathrm{hrs} 15 \mathrm{mins}$ & 230 1-phase AC & 16 & $2 / 3$ \\
\hline & $7.4 \mathrm{~kW}$ & $2 \mathrm{hrs} 35 \mathrm{mins}$ & 230 1-phase AC & 32 & $2 / 3$ \\
\hline & $14.5 \mathrm{~kW}$ & $1 \mathrm{hr} 20 \mathrm{mins}$ & 400 3-phase AC & 21 & 3 \\
\hline & $22 \mathrm{~kW}$ & $55 \mathrm{mins}$ & 400 3-phase AC & 32 & 3 \\
\hline & $43 \mathrm{~kW}$ & $30 \mathrm{mins}$ & 400 3-phase AC & 63 & 3 \\
\hline \multirow{3}{*}{$\mathrm{DC}$} & $20 \mathrm{~kW}$ & $1 \mathrm{hr}$ & 400 3-phase AC & 40 & 4 \\
\hline & $50 \mathrm{~kW}$ & $25 \mathrm{mins}$ & 400 3-phase AC & 100 & 4 \\
\hline & $100 \mathrm{~kW}$ & $15 \mathrm{mins}$ & 400 3-phase AC & 200 & 4 \\
\hline
\end{tabular}

The time it takes to charge an EV battery is dependent upon a number of factors; EVSE, charging mode (on-board or external charger), efficiency of charging equipment, battery size, battery temperature, as well as the battery level before charging commences. Table 2 provides typical charge times of a $24 \mathrm{kWh}$ battery being charged to $80 \%$.

Whilst there are a number of different charging modes, there are also numerous EV connectors both standardised and manufacturer proprietary versions, such as Tesla's version [31]. The most common versions are Type 1 and Type 2 connectors standardised under International Electrotechnical Commission (IEC) 62196; Type 1 is more popular in United States of America, while European countries mostly use Type 2 connectors. Apart from the standard electrical plugs, 3-pin and commando, all other types utilise signal lines for communication between the vehicle and power supply for safety.

It is important to note that these conductive charging systems do have associated energy losses, Sears, Roberts \& Glitman [32] identified that average charge efficiency was $85.7 \%$ when considering off peak, smart charging and different forms of charging equipment and modes. This is further reinforced by work undertaken by Forward, Glitman \& Roberts [4], there study found an average efficiency of $86.4 \%$ and Valøen \& Shoesmith [33] who identify that between 10-20\% of energy is lost in charging and discharging an EV traction battery.

With respect to dynamic conductive charging systems, Siemens and Scania have trialled catenary overhead power systems, electrical power is transferred through pantographs fitted to trucks [34]. Although a conductive charging system, it is a potential solution for the high power transfer needed for long-distance freight. Yet, requires intrusive charging infrastructure such as gantries, and raises safety issues over high voltage lines above incompletely segregated carriageway.

2.2.2 Inductive Charging: There are two main forms of WPT, near field and far field. The latter is commonly used in signal broadcasting as power levels are very low but energy transfer distances are very far. Near field is capable of higher power levels, but is limited to transferring energy to just a single wavelength from the transmitter; power rapidly decays proportionally to transfer distance [35]. Inductive Power Transfer (IPT), a form of near field WPT, utilises an inductive coupling between two magnetic fields generated by wound coils. Unlike far field, near field power transfer is non-radiative so the transferred energy remains within close proximity to the transmitter reducing issues concerning human exposure to the energy and magnetic fields [36]. In order to increase the power transfer, efficiency and range, coupled magnetic resonance is utilised in EV applications [37]. Such WPT charging technology use two resonant circuits that resonate the coils at the same frequency in order to maximise energy transfer through a Resonant Magnetic Coupling (RMC) [38]. Resonant coupling was initially pioneered by Nikola Tesla but his early experiments were only successful for very low power signal applications [39]. Advancements in electronic components has enabled further development of Resonant Inductive Power Transfer (RIPT) technology.

A further inductive charging method is the On-Line Electric Vehicle (OLEV) system, generally a similar process to RIPT but has greater potential for higher power transfer whilst using a lower resonant frequency [5]. Rather than a single transmitter pad, the coil is spread out longitudinally over the roadway enabling power transfer to occur at multiple locations along the extended coil track. Of all the WPT technologies available, RIPT (most often referred to as WPT in literature) and OLEV appear the most promising for EV applications [5]. Whilst they are separate entities, the same basic inductive principles apply, with the key difference being the sizing configuration of the coils, see Fig. 1.

A static system will see the driver park their vehicle over a ground based charging pad to receive a wireless charge to their EV. This sealed system has greater safety benefits over conductive type chargers and removes much of the inconvenience associated with continually plugging and unplugging an EV. Technically, the system rectifies the grid AC supply to DC before converting the DC power to a high frequency $\mathrm{AC}$. The high frequency $\mathrm{AC}$ is required to power the transmitter coil located underneath the vehicle, this generates an alternating magnetic field that induces a corresponding $\mathrm{AC}$ voltage within the receiving coil located on the vehicle [40]. A further $\mathrm{AC}$ to $\mathrm{DC}$ rectification process is undertaken and the DC power is used to charge the traction battery or transferred directly to the power train in DWPT applications. The shape and design of the two magnetic couplers, the transmitter and receiver coils, have a great influence on transfer efficiency. 


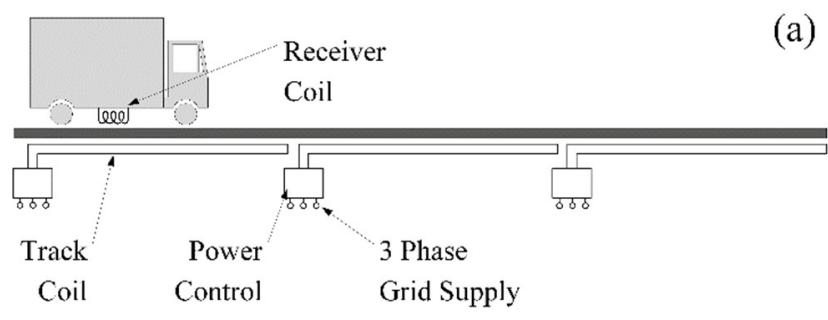

(b)

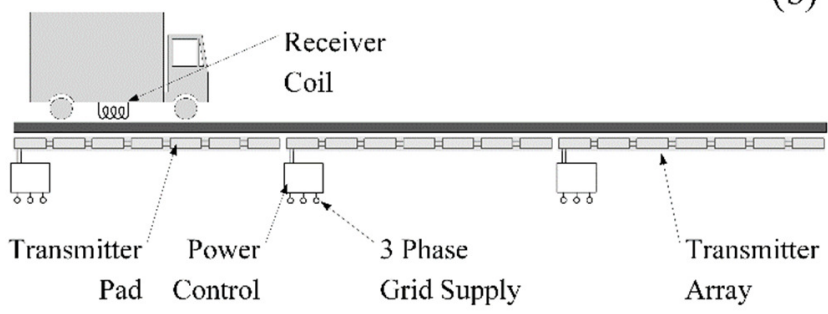

Fig. 1. Two forms of Wireless Power Transfer

(a) On-Line Electric Vehicle (OLEV), (b) Resonant Inductive Power Transfer (RIPT)

Whilst forms of WPT substantially reduce electrical safety concerns and simplify the charging process, when compared to plug in conductive systems, interoperability is still an issue. Transmitter and receiver pads must be coupled to maximise efficiency, therefore a specific operating frequency must be standardised in addition to pad design and size. Further, WPT systems are vulnerable to operational errors that will significantly decrease energy transfer efficiency, most notable lateral or longitudinal misalignment [41]. Due to the lack of cables, data communication between the vehicle and charger must now also be wireless using Dedicated Short Range Communication (DSRC) or other wireless network protocols such as Bluetooth or Wi-Fi. The subsequent sections outline the magnetic coupling design as well as the DWPT process.

\subsection{Magnetic Coupling}

The pad design is the most important factor in ensuring a high efficiency magnetic coupling between the transmitter and receiver coils. The coil design will dictate the shape of the magnetic field, thus the misalignment tolerance, leakage flux and magnetic radiation are all parameters affected by coil design [42]. For static WPT the magnetic structure follows the form of a lumped pad whilst DWPT often use an OLEV track (looped coil) type system for economic reasons. A further refinement to the track based system is to segregate the tracks into smaller loops, which in effect become a series of pads that are controlled separately. The issue with large tracks is that the receiver coil will only cover a specific region of the track that reduces the coupling efficiency and the track will emit an exposed Electromagnetic (EM) field across its energised length [7].

The structure of a magnetic pad is the culmination of a coil, ferromagnetic material and a shielding layer. Due to the high frequencies involved in WPT systems, Litz wire is typically used for the coil to compensate for high AC resistance caused by the skin effect [43]. The ferrite material is used to strengthen, guide and shape the magnetic flux. Pad magnetic structures can either be single-sided or double-sided; flux is present on both sides of double-sided pads, while only one side on single-sided pads, see Fig. 2. Li \& Mi [40] note that double-sided pads have high shielding losses due to the requirement of shielding the $\mathrm{EV}$ chassis from the EM field. Therefore, single-sided pads require much less shielding due to the majority of the flux is positioned on a single-side and only minor shielding of leakage flux is necessary.

(a)
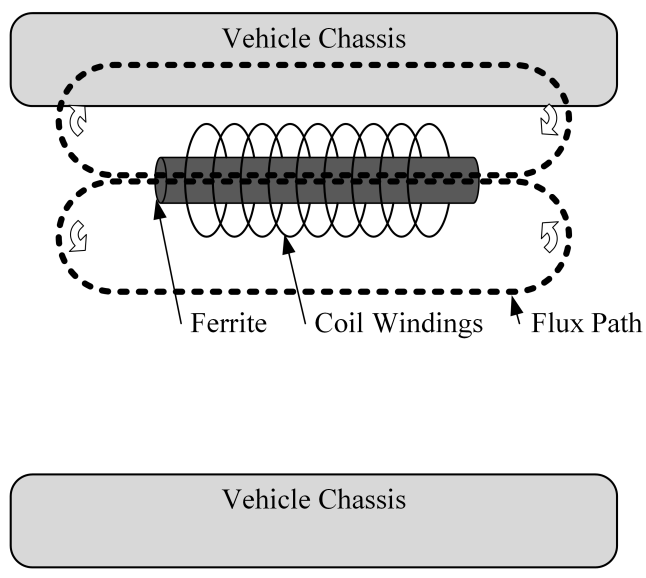

(b)

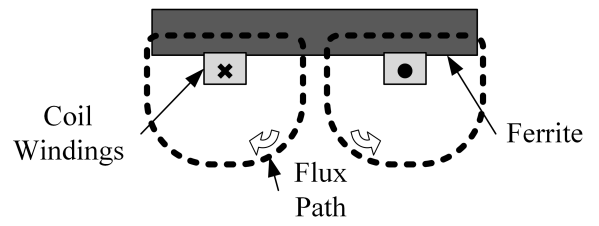

Fig. 2. Main flux path of double-sided and single-sided pads [40]

(a) Double-sided pad, (b) Single-sided pad

There are a number of different single_sided pad designs, both circular and rectangular, that are designed to enhance, often exclusively, energy transfer, misalignment tolerance and air gap transfer distance. Much work concerning the development of circular pad design and optimising ferrite layout has been undertaken by Budhia, Covic \& Boys [44]. However, a rectangular pad developed by the University of Auckland [45] has been found to significantly improve the magnetic coupling and misalignment tolerance when compared to a circular design of equal material cost. Whilst this rectangular Double D (DD) type coil has a good misalignment tolerance in the $y$ direction (longitudinal) the addition of independent quadrature coil significantly increases misalignment in the $\mathrm{x}$ direction (lateral) [45]. The resultant Double D Quadrature (DDQ) pad is capable of air gaps in excess of $30 \mathrm{~cm}$ and when receiving energy from a DD transmitter pad the effective charge zone is five times larger than a circular type pad [40], yet is more complex and expensive than other pad designs. A high coupling efficiency and quality factor enable high transfer efficiencies; in order to increase the quality factor, a high frequency is typically used, as opposed to increasing the coil structure [40]. 


\subsection{Dynamic Wireless Power Transfer}

The dynamic energy transfer process is similar to a static system but a number of changes are required to both the vehicle and infrastructure to support this. Whilst the static WPT technology discussed in Section 2.2.1 offers a wireless form of EV charging, it does little to rectify the problems associated with the vehicle remaining stationary for the duration of the charging process. Therefore, DWPT is an ideal solution to this and provides a theoretically indefinite EV range dependent upon the supporting charging infrastructure [46]. The dynamic energy transfer process is similar to a static system but a number of changes are required to both the vehicle and infrastructure to support this.

As the vehicle approaches the embedded road coils it will initiate communication between itself and the roadside signal transmitter to initiate an electronic handshake. A Road Side Unit (RSU) controls a series of charging zones, each consisting of an array of charging coils. An equipped vehicle, fitted with a receiver coil and an On Board Unit (OBU), will initiate a wireless communication between its OBU and the RSU to regulate power transfer. The purpose of this control communication is to optimise the transfer process, maintaining a high efficiency, and to ensure that coils are energised and de-energised when appropriate. Gil, Sauras-Perez and Taiber [47] evaluate both communication requirements, and the various communication technologies available.

In a DWPT process, rather than a single transmitter coil, the magnetic field is generated over a number of consecutive coils that power up as the vehicle passes over them. The length and frequency of these coils vary dependent upon the application, example systems are discussed within Section 4. Dependent upon vehicle speed this inevitably results in very short periods of time that the coils will be interacting, hence technology with a high power transfer must be used [38]. The possibility, as well as the impact, of misalignment is also greatened in a dynamic state. DWPT systems should be designed to cope with misalignment, this can be achieved through vehicle automated alignment, driver training, driver aides, road markings, coil size or coil magnetic design; various measures can be taken dependent upon cost efficiency and application scenario.

Further considerations include the magnetic field exposure to humans and the damaging affects this exposure could have public health. There is little evidence to support the impact of EM fields upon human health, International Commission on Non-Ionizing Radiation Protection state that exposure to EM field has the potential to induce current and energy absorption in human tissue [36]. They specify the maximum exposure limits as $200 \mathrm{~mA} / \mathrm{m}^{2}$ at $100 \mathrm{kHz}$ and a magnetic flux density of $27 \mu \mathrm{T}$ which appears to be conservative compared to the Institute of Electrical and Electronic Engineers guidelines that specify a flux density of $205 \mu \mathrm{T}$ [48]. Whilst the EV can incorporate active (electrical) and passive (material) shielding to reduce vehicle occupant radiation exposure, the magnetic field could pose a risk to other nearby motorists and pedestrians using the roadway if radiation exceeds stated limits. The deployment of such technology into pedestrian free areas such as motorways will negate this risk and active monitoring systems that detect and terminate the charging process when other vehicles are too close is one solution for unshielded vehicles [34]. Hui, Zhong, and Lee [49] suggest that human exposure limits will be the limiting factor when considering the maximum power transfer capabilities of DWPT systems, yet exposure limits impose limiting factors on coils and system design not necessarily power levels. With appropriate design and compensation for shielding, a system can be designed to transfer hundreds of kW's safely.

To increase DWPT efficiency, possibly to the same levels as static systems, rather than using the electrical energy to charge the battery, the energy should be transferred directly to the powertrain via an ultra or super capacitor [7], negating any charging and discharging losses of the EV battery. As long as power transfer is sufficient, the vehicle will enter and leave the charging zone with the same state of charge; however, its range has effectively been extended as no energy from the traction battery has been used to propel the vehicle over the duration of the DWPT system. Thus, DWPT avoids such battery losses resulting in a system that is more efficient than static charging methods.

It is evident that the EV charging method has an impact on EV design, on-board energy storage, vehicle mass, travel range and recharging dwell time, DWPT offers the opportunity to reduce traction battery size whilst increasing range and removing the reliance on static based charging systems. However, numerous technical aspects must be overcome to validate DWPT technology and to ensure its deployment into the road network.

\section{Dynamic Charging Infrastructure Fundamentals}

A number of vehicle and infrastructure based challenges must be overcome for the integration of WPT charging systems; not least the integration of charging pads into the road structure as well as the necessary power electronics and electricity grid reinforcement. A significant proportion of the costs concerning WPT systems concern the installation of the charging pads within the road construction. Stolte [50] states that Germany are expecting to replace a lot of their existing road infrastructure within the next 20 years, hence are looking towards installing WPT systems to reduce the installation cost but also as a means to future proof their infrastructure. The Forever Open Road project is developing the next generation of roads that are adaptable and modular in their design; communication and WPT systems could be integrated into their design [51].

The embedded coils must meet the same regulations regarding the road they are integrated into. A typical roadway is constructed from a number of aggregate layers; a flexible structure consists of a sub-grade, membrane, subbase, base course, binder course and a $4 \mathrm{~cm}$ surface course. In comparison, older rigid style roads feature a concrete section, sometimes with a $4 \mathrm{~cm}$ tarmac overlay, rather than the base and binder courses. The transmitter coils for WPT are embedded into the base course of newer flexible roads and the sub-base for rigid type roads; this ultimately affects the depth of the pad, with older rigid roads requiring fitment at a lower depth [52].

The transfer distance between the transmitter and receiver includes the air gap as well as the distance the pad is buried below the road surface [53]; hence, the increased depth of the pad in concrete sections can be problematic. Currently, a $20 \mathrm{~cm}$ coil gap appears to be sufficient for road 
installation and vehicle clearance. However, Esguerra [54] proposes the use of magnetisable concretes that are able to amplify and shape the EM field further complementing the transmitter pads. Further considerations include the robustness of the embedded coils, Gil \& Taiber [38] state the systems should be able to cope with expansion and contraction of the road surface, be sealed units, require no maintenance and should not cause issues with further road maintenance such as resurfacing which occurs periodically every 10-12 years. The resurfacing process is quite aggressive and for an average life of WPT systems being 20 years [55], the structure must be capable of withstanding at least one resurfacing process.

Due to the sealed nature of the installation, once installed, the device will not be accessible for further maintenance, servicing or upgrades achieved through technology advancements. The latter point is important in determining at what point of technology development it is appropriate to begin the deployment of such systems. Technology improvements are inevitable, but at what point is the technology efficient and future proof enough to begin installation; systems should be designed for higher power scenarios that may be achievable in the future [38]. DWPT designs that embed coils within the road but locate power electronics at the roadside do allow for some level of upgrading and maintenance without the disruption of the road surface. The installation of some WPT infrastructure will ultimately aid the development of such systems and generate advancements in further generations of the technology.

Power demand placed upon the grid should also be considered, the electrification of road transport in addition with WPT systems will create varying power demand patterns on the grid. The high frequency of energising and de-energising road base pads will generate large power spikes and appropriate roadside power electronics are necessary to compensate for this. The location of power electronics for WPT control must be located at least $2 \mathrm{~m}$ from safety barriers [55]. The length of coil energised has little effect on power requirements, since coil length will vary by just a few metres; however, energising large sections of the roadway will increase the risk of radiation exposure. The grid already experiences power spikes in the morning (6-9am) and winter evenings (5pm-8pm) [56], these times correlate with traveller commuting and WPT systems will undoubtedly increase the magnitude of electricity demand. Therefore, reinforcement and expansion of the electricity grid, including the expansion of renewables, is essential. Smart charging of vehicles, Grid to Vehicle $(\mathrm{G} 2 \mathrm{~V})$, in addition with Vehicle to Grid (V2G) systems are possible future systems that will create additional energy storage and security [57]. The use of roadside energy storage devices, such as batteries, for buffering demand requirements is another possibility, albeit increased energy losses in electrical energy conversion. Whilst electricity demand will increase, a notable reduction in fossil fuel demand will occur in parallel, thus the overall transportation energy system will balance out.

Information and Communication Technology (ICT) is an important component of WPT systems; ICT systems will be responsible for vehicle alignment to the transmitter coils, as well as Vehicle to Infrastructure (V2I) communication and road user charging of the system [58].
The V2I DSRC protocol will be responsible for initiation and monitoring of the charging process, it is recognised that this will need to be an almost real time data communication to ensure efficient alignment and energy transfer is maintained [57]. For road user charging, the amount of energy transfer is necessary in calculating the user cost; however, there is a difference between the energy sent into the transmitter coils to that received by the vehicle [59]. The type of vehicle, driver behaviour, misalignment, vehicle speed and weather conditions are just some of the factors that will affect the energy transfer and cost of electricity supplied. All energy transformation and transmission are susceptible to energy losses (primarily heat); electricity grids have transmission losses in the region of $3 \%$ to $10 \%$ of the total load [60], which inevitably are charged to the end user as would likely be the case for WPT systems. Smiai \& Winder [59] suggest the use of dynamic routing ICT systems to make route choice based upon the EV's current charge and the possible DWPT systems (once installed) between the user's origin and eventual destination.

A major challenge of DWPT is the ability to synchronise the transmitter coils to ensure that they are energised and de-energised at appropriate intervals [61]. The power electronics should ensure that the frequency of this action is fast enough to cope with typical motorway headways of $20 \mathrm{~m}$ or in some cases much smaller headways; minimum vehicle headways should be within the region of 5 to $10 \mathrm{~m}$ for the technology capabilities [62]. It is important that the system is de-energised before a traditional vehicle, without any shielding, passes over the pad due to human exposure to the EM field. Further, the system should be capable of re-energising for a further EV. Siemens and Scania have developed a lorry with active sensors to monitor if other vehicles or pedestrians are too close to the EV for dynamic charging to occur; it will switch the system on/off depending on its environment [34].

Work undertaken by Meijer [63] using PESTEL analysis suggests that probable scenarios for the deployment of WPT systems are for urban bus routes as well as long and short haul freight corridors. Whereas, urban based deployment for heavy freight, light goods and service vehicles appear less likely. The ideal scenario is for deployment to roadways that see continuous repeatable trips; therefore, initial deployment is likely to concentrate on freight and fleet vehicles that undertake such trips. On motorway links, it would be best practice to install WPT systems on the inside or dedicated lane, for example smart motorways could use the hard shoulder for a dedicated charging lane. Further applications could include dynamic charging of freight vehicles travelling at night during reduced levels of vehicle congestion. Night charging incentives could be offered for cheaper electricity that would spread the peak load demand on the grid and reduce vehicle congestion during daytime hours. The deployment of such technology nationwide for all vehicle classes is not feasible and deployment should be aimed at classes that have the most to gain.

Whilst the technology, standards and efficiencies achievable are still under review, and allowing where possible for evolution of costs over time and fluctuations in exchange rates, provisional financial costs have been proposed. Notably with specific relation to the proposer's system design, project and assumed EV proportion. The 
Transport Research Laboratory (TRL) [64] suggest infrastructure and grid connection costs are in the region of $£ 3.9$ million per $\mathrm{km}$, operation costs are $£ 1.2$ million per $\mathrm{km}$ and electricity costs are $£ 12$ million per $\mathrm{km}$ for a lifespan of 20 years. Meanwhile, an electric bus fleet feasibility study [65] concludes that infrastructure costs are $£ 0.98$ million per $\mathrm{km}$ for a 12 year lifetime. Finally, the KAIST system saw infrastructure costs of just $£ 0.25$ million per $\mathrm{km}$ [66]. As the technology is still very much underdevelopment, it is understandable that there is such a range in cost and application scenarios. Importantly, the installation and road coverage of WPT system does not need to be the entire route length, many schemes use between a 5 and $15 \%$ coverage ratio to route length [67].

It is important to consider the benefits of WPT charging systems and the monetary saving of $\mathrm{CO}_{2}, \mathrm{NOx}$ and particulate matter diversion that EV solutions provide. TRL [64] suggest that the environmental savings of WPT systems are a $45 \%$ reduction in $\mathrm{CO}_{2}$ and between $35 \%$ and $40 \%$ reduction in NOx and particulate matter. Over a 20 year lifespan, this equates to monetary values of circa $£ 2$ million per $\mathrm{km}$ for $\mathrm{CO}_{2}$ and between $£ 100 \mathrm{k}$ and $£ 1$ million per $\mathrm{km}$ for NOx and particulate matter. These values are dependent upon take up of EV dynamic charging systems and current levels of environmental pollution.

Qualcomm [68] expect that various 3rd party vehicle based pads will be produced by manufacturers, therefore these receiver designs should all function with a standardised embedded transmitter pad. Smiai \& Winder [59] recognise that standardisation is needed across a number of areas; wireless systems, grid infrastructure, coil alignment, communication protocols as well as power levels and frequencies. Standardisation is also required to specify the fitment location of the receiver pad to the base of the vehicle in order for all manufacturer systems to align themselves with the embedded coils. Specifying fitment to the vehicles centreline would alleviate most of these problems and the road based coils can be embedded to the centreline of the lane. Vehicle manufacturers state that there is only a small amount of space available for vehicle packaging of a receiver pads, typically around $20 \mathrm{~cm}^{2}$ which is far less than the size required for high power dynamic transfer and necessary misalignment tolerances. However, freight applications have considerably more space available for receiver coils. Differing vehicle air gaps will also prove problematic; freight vehicles will have different ground clearances to private passenger vehicles. The system design must be interoperable; this could be through a pad that lowers from the vehicle body for charging purposes or is through the actual receiver pad design.

The DDQ generation of receiver pads [45] currently appear to be the most efficient, but were designed for quasidynamic applications such as taxi rank charging systems. The quantity of pads required and their higher respective costs, result in them not being a feasible choice for DWPT applications. Instead much longer and simpler coils are required to simplify the system whilst minimising costs. Systems should be capable of high transfer efficiencies with a driver misalignment of up to $15 \mathrm{~cm}$ [55]. Covic \& Boys [7] recognise that there is a notable increase in efficiency when using the energy transferred from WPT systems directly for the powertrain motorisation rather than charging the battery. Such a scenario increases efficiency beyond that of static
WPT systems and effectively extends the vehicles range as the time it spends over the DWPT system are additional miles gained.

The following factors are identified as the most influential parameters that affect energy transfer efficiency of a DWPT scenario; such parameters exist within four main categories. It is important to distinguish between what efficiency the system is technically capable of, assuming a perfect driving scenario, and the proportion of error an average driver induces. The wider system network factors are not unique to DWPT applications; many of these power supply infrastructure points would be applicable to other charging applications.

Wider system network:

- Location of charging lanes

- Grid supply capabilities

- Voltage and frequency of power transmission

- Weather conditions

Problems and errors:

- Foreign objects in charging zone

- Proximity of pedestrians or other vehicles that will cause charging to terminate

- Installation and manufacturing errors

Vehicle and infrastructure interaction:

- Air gap; vehicle ground clearance and depth of embedded coil

- Binder and surface course material; their magnetic properties

- EV design; i.e. mass, traction batteries, motor efficiency, electrical convertors

- Direct power feed to motor or via traction batteries

- Vehicle and embedded coil/loop design and switching speed of primary coils

- V2G/G2V communication capabilities and speed

- Associated power electronics to power primary coils; i.e. inverter designs, cooling systems

Human driving properties:

- Vehicle coil to embedded coil alignment

- Vehicle speed and acceleration

- Elapsed time spent in charging lane

Much work has been undertaken within academia and research institutions in assessing the viability and scope of WPT technology for EV charging applications, whilst it has been validated as a feasible technology, it is important to assess the latest state-of-the-art systems being developed and deployed by industry.

\section{State-of-the-Art in WPT Systems}

There are a number of organisations developing both static and dynamic WPT solutions, some of which are market ready and many more still under laboratory development. The most notable work concerning DWPT includes systems developed by Korea Advanced Institute of Science and Technology (KAIST), Bombardier and Qualcomm.

Other systems include; the SIVETEC static WPT system developed by Siemens as well as the market ready 
WiTricity static WPT system originally developed at Massachusetts Institute of Technology. The scalable WiTricity system is capable of transferring power from $3.6 \mathrm{~kW}$ to $11 \mathrm{~kW}$ at efficiencies greater than $90 \%$ [69]. The system integrates Foreign Object Detection (FOD) and Live Object Detection (LOD) for monitoring the charging environment for both metallic objects (FOD) and humans or animals (LOD).

The Oak Ridge National Laboratory has also undertaken notable work concerning WPT systems, having recently achieved a $95 \%$ efficiency of a static $20 \mathrm{~kW}$ WPT system over a $16 \mathrm{~cm}$ air gap [70]. Meanwhile, Utah State University have developed and demonstrated static systems of up to $25 \mathrm{~kW}$ with laboratory efficiencies greater than $90 \%$ achieved [71]. Whilst these efficiencies appear high, Barrett [50] states that conductive charging is usually 1 to $2 \%$ more efficient than WPT systems, however if the WPT system is used in a dynamic state (directly powering the motors) it is more efficient. Further, laboratory testing is vastly different to real world testing where other factors and scaling of the system will ultimately affect efficiencies stated.

According to TRL, KAIST have developed the most market ready DWPT solution [72]. Their OLEV project has been in progress since 2009 and has seen the development of five generations of OLEV systems. KAIST's first generation OLEV system was capable of a $3 \mathrm{~kW}$ power transfer over a $1 \mathrm{~cm}$ air gap, misalignment tolerance was just $3 \mathrm{~mm}$ with a transfer efficiency of $80 \%$ [42]. Continual development has resulted in a real world system capable of transferring power levels of $100 \mathrm{~kW}$ over a $20 \mathrm{~cm}$ air gap. Through development of both the power rail track and onboard receiver pad, misalignment tolerances have been increased to $20 \mathrm{~cm}$ with an efficiency of $83 \%$. Reducing the air gap sees transfer efficiency greater than $90 \%$ but regulations mandate a minimum vehicle ground clearance in many cases [73]. Essentially, all of the KAIST OLEV generation meet the specified human exposure EM field emission limits regulated by International Commission on Non-Ionizing Radiation Protection [36].

The KAIST system is licensed to OLEV Technologies, the various generations of the technology have been trialled since 2010 and there are two commercial systems still in operation; the KAIST shuttle bus and a public bus service in Gumi City, South Korea [73]. Whilst the shuttle bus service has a minor route of just $3.76 \mathrm{~km}$ segregated from other road vehicles, the public bus service has a length of $35 \mathrm{~km}$ with numerous charging zones and is integrated with other road vehicles [72]. Although the system features DWPT technology, it was implemented for demonstration purposes and the particular bus route does not require dynamic charging, hence only static charging is currently utilised. The systems are the same, a single coil is used for static charging and multiple coils for dynamic charging.

The Gumi City buses receive a full charge before leaving the depot, and then opportunistic charging via the OLEV systems is used to maintain sufficient energy to complete the route. By implementing charging zones at key areas, such as around bus stop locations, takes advantage of the slower transit speeds witnessed when a bus is decelerating and accelerating. The system is also capable of static wireless charging, both at the bus depot and when the bus passengers are boarding and alighting. The power rails remain switched off until an OLEV compatible vehicle approaches, the rails then power up once the bus is overhead. A directional indicator is used by the driver to accurately align the power rail and bus receiver pad to maximise energy transfer. Due to the high power transfer and opportunistic charging process, battery capacity is five times less than a non-WPT enabled electric transit system. Further, as only accelerating regions, junctions, bus stops and depot bays require OLEV charging systems, infrastructure costs are less than $£ 0.32$ million per $\mathrm{km}$, including power electronics and embedded power rails [66].

The approach taken by Bombardier and their PRIMOVE program is to concentrate on sustainable mobility through several key areas; wireless charging, traction batteries and propulsion systems across both road and rail transportation modes [74]. Their WPT system was developed as a dynamic system for catenary-less trams but then turned into high power static WPT system for buses as the business case and exploitation route for this implementation was more near-market. A commercial vehicle based system includes a $3.6 \mathrm{~kW}$ home based charger that is also scalable to $22 \mathrm{~kW}$ for fast charging applications. Bombardier also developed a Z-Mover for static WPT, the transmitter pad will lift up to meet the receiver coil when a compatible vehicle is parked above the pad. This effectively reduces the air gap to an optimised distance in order to increase efficiency whilst allowing fitment to various types of vehicles with both small and large ground clearances.

Further road trials and installed commercial systems include a number of bus routes in Belgium and Germany, charging stations are located at bus stops, end of the line stops as well as the bus depot. Buses receive a full charge before leaving the bus depot and opportunistic top-up charging is carried out when the bus is stationary at any of the charged bus stops. Due to the short dwell times, the WPT system has a high power rating of $200 \mathrm{~kW}$ with reported efficiencies greater than $90 \%$ according to Bombardier [74]. Whilst PRIMOVE primarily concentrates on static based systems, Bombardiers WPT system was tested during the Flanders' DRIVE research project and trials have been undertaken in Mannheim for a truck based $200 \mathrm{~kW}$ dynamic charging system as well as a tram based system.

Initially a research project, Qualcomm purchased the Halo IPT project in 2011 from the University of Auckland and Arup who first developed the project over the twenty years prior to Qualcomm's acquisition [75]. Qualcomm has extensively developed static based systems for home use with power levels of $3.7 \mathrm{~kW}$ through to $22 \mathrm{~kW}$ systems. Such systems have been trialled in London for car sharing schemes and used for media awareness in charging Formula E's safety cars. A licensing agreement between Qualcomm and Ricardo is set to commercialise Qualcomm's EV static WPT charging system. Ricardo will design and manufacture the system with the aim of developing the product for direct supply to automotive manufacturers.

Qualcomm state that their static system can achieve $97 \%$ efficiency over the actual air gap, with a $90 \%$ efficiency from the grid supply to vehicle electronics [76]. The maximum misalignment tolerance is $20 \mathrm{~cm}$. In addition to their static system, Qualcomm are invested in developing both quasi-dynamic, for slow moving traffic and taxi ranks, and fully dynamic WPT systems. Qualcomm have stated 
that they are keen for, and continually assist, policymakers in standardising WPT technology to ensure interoperability between manufacturers and vehicles whilst also generating the growth of WPT systems needed to reduce manufacturing costs [41]. Interoperability is a key component of Qualcomm's design, Qualcomm state that a standardised transmitter pad or track should be mandated and various 3rd party vehicle fitted receiver coils must be designed to support such transmitters [68]. Without such standards, issues concerning interoperability between vehicles and varying charging infrastructure will hamper the take-up and potential of DWPT systems. Each of the systems proposed by KAIST, Bombardier and Qualcomm are functional and effective in their own designs, but are not compatible with one another. Standardising infrastructure electronics will provide manufacturers with the necessary reference specification to develop their systems for, without the risk of incompatible systems as seen with the wide array of conductive plug types and charging stations.

\section{International Standards of Electric Vehicles \& Associated Technologies}

There are a number of organisations currently working on the standardisation of WPT systems and associated technologies; this includes the global organisations International Organisation for Standardisation (ISO) and International Electrotechnical Commission (IEC) as well as the American based organisation Society of Automotive Engineers (SAE). The main reason for standardisation of WPT systems is for interoperability and safety; standards should not stifle competition or restrict the development of WPT technology but provide a reference system to manufacturers [77]. At present, manufacturers typically produce dynamic or static based systems as individual entities rather than a single coherent system. Table 3 contains standards relevant to WPT systems and other associated technologies; it should be noted that not all standards are finalised and many are still under development.

Leading standards are currently ISO 19363, IEC 61980 and SAE J2954. The ISO 19363 standard covers EV architecture, WPT, safety and interoperability aspects. The IEC 61980 standard series consists of several parts that cover the general system, EV and infrastructure communication system as well as inductive wireless power transfer requirements. Whilst the SAE J2954 (still under development) covers similar aspects to the other standards, it is specific in its power range and application, 3.7 to $22 \mathrm{~kW}$ static WPT systems; higher power and dynamic systems may be considered in future revisions [78]. ISO and SAE recently agreed to collaborate with the aim of jointly developing the ISO 19363 and SAE J2954 standards to produce a single standard specifying the minimum performance, safety criteria, technology evaluation and common WPT charging system approach [79]. Whilst not mandatory like regulations, standards remove difficulties in developing technologies or bringing new technologies to market through standardising relevant aspects, ultimately accelerating the rate of market penetration and technology growth. Standards will assist and create growth of WPT technologies, as they have done and continue to do for EV's [80].

Future WPT systems should be capable of matching the efficiency benchmark set by conductive systems, $>85 \%$ according to SAE J1772 standard [81-82]. Standardisation of the system architecture, operating frequency, coil alignment tolerances and efficiencies are essential to ensure interoperability. Whilst coil design can vary per vehicle, the embedded coil and infrastructure architecture should be standardised for manufacturers to develop their own vehicle based systems that are optimised against the infrastructure system. Whilst work is continuing in this area, the current maturity of technology and technical complexity are the main barriers to standardisation, yet the standards are still in advance of the market that continues to shape and develop such standards [83]. However, standardisation is now paramount to ensure that the infrastructure system design is standardised, allowing manufacturers to optimise their systems to the infrastructure and to ensure that the technology reaches the point of market deployment. Until system architectures are finalised, from the operating frequency to the shape of the magnetic coupling, road based

Table 3 Wireless charging and relevant technology standards

Standard

Topic

ISO 19363

ISO 15118

ISO 17409

ISO 12405

ISO 6469

\begin{tabular}{l}
\hline IEC 61980 \\
IEC 62840 \\
IEC 61851
\end{tabular}

SAE J2954

SAE 1772

SAE J1773

SAE J2836/6

SAE J2847/6

SAE J2931/6

BS EN 61851-1
Electrically propelled road vehicles - magnetic field wireless power transfer - safety and interoperability requirements

Road vehicles - vehicle to grid communication interface

Connection to external electric power supply

Li-Ion battery system - performance testing and safety performance

Electrically propelled road vehicles - safety specifications

\section{Electric vehicle wireless power transfer systems}

Electric vehicle battery swap system

Electric vehicle conductive charging system

\section{Wireless charging of electric and plug-in hybrid vehicles}

Electric vehicle and plug in hybrid electric vehicle conductive charge coupler

Electric vehicle inductively coupled charging

Use cases for wireless charging communication for plug-in electric vehicles

Communication between wireless charged vehicles and wireless EV chargers

Signalling communication for wirelessly charged electric vehicles

Electric vehicle conductive charging system: general requirements 
trials and eventual deployment are hindered. The most important factors that should be developed into current standards are:

\section{- System frequency}

- Human exposure safety criteria

- Location of the coil to the centreline of the vehicle and lane

- Driver assistance systems to maximise vehicle lane alignment.

- Interoperability between static and dynamic WPT systems

- Bi-directional energy transfer capabilities to maximise the scope for both $V 2 G$ and $G 2 V$ possibilities

\section{Conclusions}

EV's have the ability to significantly reduce the transport industries reliance on fossil fuels, lower transport related $\mathrm{CO}_{2}$ emissions and improve air quality within cities. It is evident by the literature reviewed that DWPT systems are capable of increasing EV market penetration, increasing vehicle range, reducing $\mathrm{EV}$ costs as well as reducing transport energy consumption through reduction in traction battery mass and higher electricity transfer efficiencies. Whilst WPT systems increase user safety and convenience, DWPT systems are capable of achieving higher efficiencies when making transferred power exclusively available for the EV motors, thus removing energy losses that occur when transferring energy in and out of a traction battery. These losses also pose a threat to the practicality of V2G possibilities.

Plug-in or static WPT charging within home environments will still play a key component within the entire charging infrastructure; it provides both a convenient and low cost method of EV charging. Whenever the vehicle is stationary for long periods of time, at night and during the working day, it is beneficial to use efficient static charging systems. The peak load demand on the electricity grid is lessened with home charging as the majority of charging will be undertaken overnight. The continued efforts to electrify the road transport industry will inevitably increase demand on the electricity grid, it is essential that this is reinforced and work undertaken towards a coordinated smart grid where ICT solutions and smart charging assist in managing load demand. It is unclear at this current time if V2G systems are feasible due to the poor energy transfer efficiencies of EV traction batteries. Nevertheless, additional energy storage is required to cope with the peak electricity demand that currently occurs, which will undoubtedly increase in magnitude as the EV market takeup continues.

Standardisation is also necessary in all areas concerning WPT systems, most important is the need to standardise the road based transmitter design. It is expected that 3rd party companies will produce their own receiver type pads for vehicle fitment, but without a standardised embedded transmitter and grid side power electronics, transfer efficiencies will not be maximised and system interoperability will not be achieved. Another concern is the fitment of receiver pads to the vehicle, these must be standardised to ensure that the vehicle will naturally align the receiver and transmitter coils when in the middle of a lane. Standardisation will also assist to limit and control human exposure to the EM field, research has shown that through optimising the magnetic coupling design, transfer energy can remain high whilst containing the EM field.

The most likely scenario for DWPT deployment are freight corridors where repeatable trips are expected. While Meijer [63] proposes that urban bus solutions are a viable DWPT use case, when buses are boarding and alighting they are stationary, allowing the use of flash charging if necessary. A far more cost effective and simpler method, with respect to infrastructure requirements, than DWPT systems. A further application would be to subsidise overnight use of DWPT systems to help spread peak load electricity demand and reduce daytime congestion levels. The use of ICT solutions to provide a degree of autonomy to vehicles using DWPT could regulate vehicle headways and speeds to maximise energy transfer efficiency, similar to vehicle platooning already being tested. It is important that initial deployment scenarios maximise the technologies impact with the minimum quantity of infrastructure and technology. Whilst freight corridors experiencing repeatable trips are good initial deployment locations, the technology should be scalable to enable the eventual wider capture of private and smaller class vehicles. Whilst there are a number of feasible deployment strategies, the future optimised charging infrastructure will inevitably be the culmination of plug-in, static and dynamic WPT solutions.

\section{Acknowledgments}

The authors would like to acknowledge the support from the Engineering and Physical Sciences Research Council (EPSRC) under Centre for Doctoral Training grant EP/L01582X/1 in partnership with the Transport Research Laboratory (TRL).

\section{References}

[1] Yong, J.Y., Ramachandaramurthy, V.K., Tan, K.M., et al.: 'A review on the state-of-the-art technologies of electric vehicle, its impacts and prospects', Renewable and Sustainable Energy Reviews., 2015, 49, pp. 365-385

[2] Eberle, U., and von Helmolt, R.: 'Sustainable transportation based on electric vehicle concepts: a brief overview', Energy \& Environment Science, 2010, 3, pp. 689-699

[3] Bullis, K.: 'Why We Don't Have Battery Breakthroughs', https://technologyreview.com/s/534866/why-we-dont-havebattery-breakthroughs, accessed 1 December 2017

[4] Forward, E., Glitman, K., and Roberts, D.: 'An Assessment of Level 1 and Level 2 Electric Vehicle Charging Efficiency' (Vermont Energy Investment Corporation, Burlington, 2013), pp. 1-16

[5] Musavi, F., and Eberle, W.: 'Overview of wireless power transfer technologies for electric vehicle battery charging,' IET Power Electronics., 2014, 7, (1), pp. 60-66 
[6] Heuss, R., Müller, N., Sintern, W.V., et al.: 'Lightweight, heavy impact', (McKinsey \& Company, London, 2012), pp. $1-24$

[7] Covic, G.A., and Boys, J.T.: 'Modern Trends in Inductive Power Transfer for Transportation Applications', IEEE Journal of Emerging and Selected Topics in Power Electronics, 2013, 1, (1), pp. 28-41

[8] Chan, C.: 'Advances in Electric Vehicles', HKIE Transactions., 2013, 10, (4), pp. 1-13

[9] International Energy Agency.: 'Global EV Outlook 2017' (IEA Publications, Paris, 2017)

[10] Staufenberg, J.: 'Norway to 'completely ban petrol powered cars by $2025^{\prime \prime}$,

http://independent.co.uk/environment/climate-

change/norway-to-ban-the-sale-of-all-fossil-fuel-based-carsby-2025-and-replace-with-electric-vehicles-a 7065616.html, accessed 1 December 2017

[11] Office for National Statistics.: '2011 Census Analysis Distance Travelled to Work' (The Stationery Office,

London, 2014)

[12] Dizikes, P.: 'Will we ever stop using fossil fuels?', http://news.mit.edu/2016/carbon-tax-stop-using-fossil-fuels0224, accessed 1 December 2017

[13] Baruah, P., Chaudry, M., Qadrdan, M., et al.: 'Energy Systems Assessment', in Hall, J., Tran, M., Hickford A., et al (Eds.): 'The Future of National Infrastructure: A System of Systems Approach', (Cambridge University Press, Cambridge, 2016, 1st edn.), pp. 54-87

[14] Automotive Councils UK.: 'Automotive technology roadmaps' (Automotive Councils UK, London, 2013)

[15] Lu, L., Han, X., Li, J., et al.: 'A review on the key issues for lithium-ion battery management in electric vehicles', Journal of Power Sources, 2013, 226, pp. 272-288

[16] Wakihara, M.: 'Recent developments in lithium ion batteries', Materials Science and Engineering., 2001, 33, (4), pp. $109-134$

[17] Scrosati, B., and Garche, J.: 'Lithium batteries: Status, prospects and future', Journal of Power Sources, 2010, 195, pp. $2419-2430$

[18] Husain, I.: 'Electric and Hybrid Vehicles: Design Fundamentals,' (CRC Press, Boca Raton, 2011, 2nd edn.)

[19] Knupfer, S., Hensley, R., Hertzke, P., et al.: 'Electrifying insights: How automakers can drive electrified vehicles sales and profitability' (McKinsey \& Company, New York, 2017)

[20] Langan, C.: 'UBS Sees Tesla's (TSLA) Model 3 As Unprofitable',

https://streetinsider.com/Analyst+Comments/UBS+Sees+Te
lsas+\%28TSLA\%29+Model+3+As+Unprofitable/11540932. html?si_client=st, accessed 1 December 2017

[21] Burke, A.: 'Comparisons of Lithium-ion batteries and ultra capacitors in hybrid-electric vehicle applications', 2nd European Electric-Drive Transportation Conference, Brussels, Belgium, May 2007, pp. 1-9

[22] Luntz, A.C., Voss, J., and Reuter, K.: 'Interfacial Challenges in Solid-State Li Ion Batteries', Journal of Physical Chemistry Letters, 2015, 6, (22), pp. 4599-4604

[23] Arora, S., Shen, W., and Kapoor, A.: 'Review of mechanical design and strategic placement technique of a robust battery pack for electric vehicles', Renewable and Sustainable Energy Reviews, 2016, 60, pp. 1319-1331

[24] Clement-Nyns, K., and Haesen, E.: 'The Impact of Charging Plug-In Hybrid Electric Vehicles on a Residential Distribution Grid', IEEE Transactions on Power Systems, 2010, 25, (1), pp. 371-380

[25] BEAMA.: 'A Guide to Electric Vehicle Infrastructure', (BEAMA, London, 2015), pp. 1-40

[26] Falvo, M.C., Sbordone, D., Bayram, I.S., and Devetsikiotis, M.: 'EV Charging Stations and Modes: International Standards', International Symposium on Power Electronics, Electrical Drives, Automation and Motion (SPEEDAM), Ischia, Italy, June 2014, pp. 1134-1139

[27] British Standards Institution.: 'Electric vehicle conductive charging system. General requirements', BS EN 61851-1:2011

[28] Zap Map.: 'Charging Basics', https://zapmap.com/charge-points/basics, accessed 1 December 2017

[29] Braunl, T.: 'EV Charging Standards' (University of Western Australia, Perth, 2012), pp. 1-5

[30] Bicheno, P.: 'Electric Vehicle Charging Equipment', (Institution of Engineering and Technology, Stevenage, 2011), pp. 24-28

[31] Rajagopalan, S., Maitra, A., Halliwell, J., et al.: 'Fast Charging: An In-Depth Look At Market Penetration, Charging Characteristics, and Advanced Technologies', International Battery, Hybrid and Fuel Cell Electric Vehicle Symposium, Barcelona, Spain, November 2013, pp. 1-11

[32] Sears, J., Roberts D., and Glitman, K.: 'A Comparison of Electric Vehicle Level 1 and Level 2 Charging Efficiency', IEEE Conference on Technologies for Sustainability (SusTech), Portland, United States of America, July 2014, pp. 1-4

[33] Valøen, L.O., and Shoesmith, M.I.: 'The Effect of PHEV and HEV Duty Cycles on Battery and Battery Pack Performance' (University of Manitoba, Winnipeg, 2007), pp. $1-9$ 
[34] Scania Group.: 'Scania tests next-generation electric vehicles', https://scania.com/group/en/scania-tests-nextgeneration-electric-vehicles, accessed 1 December 2017

[35] Qiu, C., Liu C., and Chan, C.C.: 'Overview of Wireless Power Transfer for Electric Vehicle Charging', European Green Vehicles Initiative 27, Barcelona, Spain, November 2013, pp. 1-9

[36] International Commission on Non-Ionizing Radiation Protection.: 'Guidelines for limiting exposure to time varying electric and magnetic fields $(1 \mathrm{~Hz}-100 \mathrm{kHz})$, Health Physics, 2010, 99, (6), pp. 818-836

[37] Sabki, S.A., and Tan, N.M.L.: 'Wireless Power Transfer for Electric Vehicles’, Langkawi, 2014.

[38] Gil, A., and Taiber, J.: 'A Literature Review in Dynamic Wireless Power Transfer for Electric Vehicles: Technology and Infrastructure Integration Challenges' in Wellnitz, J (Eds.): 'Sustainable Automotive Technologies', (Springer International Publishing, Switzerland, 2013, 1st edn.), pp. 289-298

[39] Wheeler, L.P.: 'Tesla's contribution to high frequency', Electrical Engineering, 1943, 62, (8), pp. 355-357

[40] Li, S., and Mi, C.C.: 'Wireless Power Transfer for Electric Vehicle Applications', IEEE Journal of Emerging and Selected Topics in Power Electronics, 2015, 3, (1), pp. 4-17

[41] Qualcomm.: 'Halo IPT - Frequently Asked Questions' (Qualcomm, San Diego, 2016), pp. 1-4

[42] Choi, S.Y., Gu, B.W., Jeong S.Y, et al.: 'Advances in Wireless Power Transfer Systems for Roadway-Powered Electric Vehicles', IEEE Journal of Emerging and Selected Topics in Power Electronics, 2015, 3, (1), pp. 18-36

[43] Miller, J.M., White, C.P., Onar, O.C., et al.: 'Grid side regulation of wireless power charging of plug-in electric vehicles' (Oak Ridge National Laboratory, Raleigh, 2012), pp. $1-8$

[44] Budhia, M., Covic, G.A., and Boys, J.T.: 'Design and Optimization of Circular Magnetic Structures for Lumped Inductive Power Transfer Systems', IEEE Transactions on Power Electronics, 2011, 26, (11), pp. 3096-3108

[45] Boys, J.T., and Covic, G.A.: 'IPT Fact Sheet Series: No.1 - Basic Concepts' (University of Auckland, Auckland, 2012), pp. 1-7

[46] Maglaras, L.A., Jiang, J., Maglaras, et al.: 'Dynamic wireless charging of electric vehicles on the move with Mobile Energy Disseminators', International Journal of Advanced Computer Science and Applications, 2015, 6, (6), pp. 239-251

[47] Gil, A., Sauras-Perez, P., and Taiber, J.:

'Communication Requirements for Dynamic Wireless

Power Transfer for Battery Electric Vehicles', IEEE
International Electric Vehicle Conference, Florence, Italy, December 2014, pp. 1-24

[48] Institute of Electrical and Electronic Engineers.: 'Standard for Safety Levels with Respect to Human Exposure to Radio Frequency Electromagnetic Fields, $3 \mathrm{kHz}$ to $300 \mathrm{GHz}$ ' (IEEE International Committee on Electromagnetic Safety, New York, 2006), pp. 1-250

[49] Hui, S.Y.R., Zhong, W., and Lee, C.K., 'A Critical Review of Recent Progress in Mid-Range Wireless Power Transfer', IEEE Transaction on Power Electronics, 2014, 29, (9), pp. 4500-4511

[50] Stolte, P., Barrett, J., Thomson, A., et al: 'Your questions answered: inductive charging for road vehicles', https://theengineer.co.uk/issues/march-2013-online/yourquestions-answered-inductive-charging-for-road-vehicles, accessed 1 December 2017

[51] Lamb, M.J., Collis, R., Deix, S., et al.: 'The Forever Open Road - Defining the next generation road', (Transport Research Laboratory, Crowthorne, 2013)

[52] Naberezhnykh, D.: 'Wireless Power Transfer technologies for EVs', 21st ITS World Congress, Michigan, United States of America, 2014.

[53] Chen, F., Birgisson, B., and Kringos, N.:

'Electrification of Roads: Infrastructural Aspect' (KTH Royal Institute of Technology, Stockholm, 2015), pp. 1-14

[54] Esguerra, M.: 'Magnetizable concretes as a competitive and road integrable solution to increase the efficiency and/or coil distance for DWPT', FABRIC: Wireless Dynamic Charging for FEVs: Challenges and Concepts, Brussels, Belgium, February 2016, pp. 1-10

[55] Naberezhnykh, D.: 'Dynamic Wireless Power Transfer', Conference on Electric Roads and Vehicles, Logan, United States of America, May 2015, pp. 1-18

[56] Department for Business, Energy and Industrial Strategy.: 'Energy Consumption in the UK' (The Stationary Office, London, 2016), pp. 1-39

[57] Damousis, Y.: 'FABRIC: Feasibility analysis and development of on-road charging solutions for future EVs', IEEE International Electric Vehicle Conference, Florence, Italy, December 2014, pp. 1-24

[58] Amditis, A.: "FABRIC: "Feasibility analysis and development of on-road charging solutions for future electric vehicles"," European Electric Vehicle Congress, Brussels, Belgium, December 2014, pp. 1-16

[59] Smiai, O., and Winder, A.: 'ICT Requirements for OnRoad Electric Vehicle Charging', ITS World Congress, Bordeaux, France, October 2015, pp. 1-10

[60] Ramos, J.L.M., and Quintana, V.H.: 'Optimal and Secure Operation of Transmission Systems', in Expósito, A., Conejo, A.J., and Cañizares, C. (Eds.): 'Electric Energy 
Systems: Analysis and Operation', (CRC Press, Boca Raton, 2008, $1^{\text {st }}$ edn.), p. $211-264$

[61] Taiber, J.G.: 'Building a testbed for EV wireless charging solutions - experiences and thoughts for standardization aspects', IEEE International Electric Vehicle Conference, Florence, Italy, December 2014, pp. 1-15

[62] Theodoropoulos, T., Damousis, Y., Amditis, A., et al.: 'EV Wireless Charging Demand Analysis for various Traffic Patterns and Environments', ITS and Smart Cities, Patras, Greece, November 2014, pp. 1-23

[63] Meijer, S.: 'Identifying first deployment feasibility: separating unrealistic from real options', FABRIC: Wireless Dynamic Charging for FEVs: Challenges and Concepts, Brussels, Belgium, February 2016, pp. 1-13

[64] Transport Research Laboratory.: 'The feasibility of using Dynamic Wireless Power Transfer for EVs', FABRIC: Wireless Dynamic Charging for FEVs: Challenges and Concepts, Brussels, Belgium, February 2016, pp. 1-14

[65] Shekhar, A., Prasanth, V., Bauer P., et al.: 'Economic Viability Study of an On-Road Wireless Charging System with a Generic Range Estimation Method', Energies, 2016, 9, (2), pp. 1-20

[66] Huh, J., Cho, G.H., Lee, W., et al.: 'Characterization of Novel Inductive Power Transfer Systems for On-Line Electric Vehicles' (IEEE, Fort Worth, 2011), pp. 1-5

[67] Suh, N.P.: 'Wireless Power Transfer for Electric Vehicles', in Suh, N.P., and Cho, D.H. (Eds.): 'The On-Line Electric Vehicle', (Springer International Publishing, Switzerland, 2017, 1st edn.), p. 17-34

[68] Qualcomm.: 'The Future of Road Transportation is Electric and Wireless' (Qualcomm, San Diego, 2016), pp. 114

[69] WiTricity.: 'Automotive Applications', http://witricity.com/applications/automotive, accessed 1 December 2017

[70] Onar, O.C., Campbell, S., Seiber, L., et al.: 'Oak Ridge National Laboratory Wireless Charging of Electric Vehicles - CRADA Report', (Oak Ridge National Laboratory, Oak Ridge, 2016), pp. 1-18

[71] Morris, C.: 'The Dynamic Road Ahead: Utah State University builds a dynamic wireless charging test track', in Ruoff, C. (Eds.): 'Charged Electric Vehicles Magazine', (Isentropic Media, 2014), pp. 82-87

[72] Transport Research Laboratory.: 'Feasibility Study: Powering electric vehicles on England's major roads' (Highways England, London, 2015), pp. 1-252

[73] Rovito, M.: 'On the Right Track: OLEV Technologies', in Ruoff, C. (Eds.): 'Charged Electric Vehicles Magazine', (Isentropic Media, 2014), pp. 70-75
[74] Bombardier.: 'PRIMOVE True Mobility', http://primove.bombardier.com, accessed 1 December 2017

[75] Qualcomm.: 'Qualcomm Halo', https://qualcomm.com/products/halo, accessed 1 December 2017

[76] Qualcomm.: 'Wireless Charging for Electric Vehicles No fuss, just wireless', (Qualcomm, San Diego, 2016), pp. $1-6$

[77] Woronowicz, K.: 'Standardization Questions', 15th IEEE International Vacuum Electronics Conference, Monterey, United States of America, April 2014, pp. 1-12

[78] Society of Automotive Engineers J2954: 'Wireless Power Transfer for Light-Duty Plug-In/ Electric Vehicles and Alignment Methodology, Work in Progress

[79] Society of Automotive Engineers.: 'Two leaders join forces for the development of standards in automotive', http://sae-europe.org/news-posts/two-leaders-join-forcesdevelopment-standards-automotive, accessed 1 December 2017

[80] Pereirinha, P.G., Trovão, J.P.: 'Standardisation in Electric Vehicles', 12th Portuguese-Spanish Conference on Electrical Engineering, Ponta Delgada, Portugal, June 2011, pp. 1-5

[81] Society of Automotive Engineers J1772: 'SAE Electric Vehicle and Plug in Hybrid Electric Vehicle Conductive Charge Coupler', 2010

[82] Miller, J.M., Jones, P.T.: 'Wireless Charging', (Oak Ridge National Laboratory, Oak Ridge, 2013), pp. 1-27

[83] Marengo, L.: 'Fast in Charge - Innovative fast inductive charging solutions for electric vehicles', (Fiat Research Centre, Orbassano, Italy), 2015, pp. 1-8 